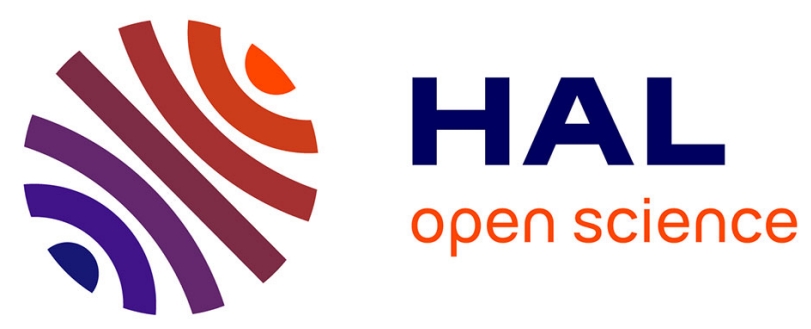

\title{
Classification of brightness temperature components for a maize canopy
}

\author{
Tao Yu, Guoliang Tian, Yonghong Lv, Roland Bosseno, Xingfa Gu, \\ Jean-François Hanocq, Michel Legrand
}

\section{- To cite this version:}

Tao Yu, Guoliang Tian, Yonghong Lv, Roland Bosseno, Xingfa Gu, et al.. Classification of brightness temperature components for a maize canopy. IEEE international geoscience and remote sensing symposium, Jul 2003, Toulouse, France. 10.1109/IGARSS.2003.1294400 . hal-02763758

\section{HAL Id: hal-02763758 \\ https://hal.inrae.fr/hal-02763758}

Submitted on 11 Aug 2021

HAL is a multi-disciplinary open access archive for the deposit and dissemination of scientific research documents, whether they are published or not. The documents may come from teaching and research institutions in France or abroad, or from public or private research centers.
L'archive ouverte pluridisciplinaire HAL, est destinée au dépôt et à la diffusion de documents scientifiques de niveau recherche, publiés ou non, émanant des établissements d'enseignement et de recherche français ou étrangers, des laboratoires publics ou privés. 


\section{Classification of brightness temperature components for a maize canopy}

\author{
Tao YU, Guoliang TIAN, Yonghong Lv \\ LARSIS-IRSA-CAS, Beijing, China \\ e-mail: yutao@irsa.irsa.ac.cn
}

\author{
Roland Bosseno \\ IRD / CSE-INRA, Avignon, France \\ e-mail: rbosseno@avignon.inra.fr
}

\author{
Xingfa GU, Jean-Francois Hanocq \\ CSE-INRA, Avignon, France \\ e-mail: gu@avignon.inra.fr
}

\author{
Michel LEGRAND \\ Université des Sciences et Technologies de Lille \\ e-mail: legrand@loa.univ-lille1.fr
}

\begin{abstract}
In order to modeling directional thermal radiation and energy balance for a partially covered canopy, surface brightness temperature is usually classified into several components. This paper researches on the methodology for brightness temperature component classification and temporal variations of component number and values by an in situ experiment, dedicated to analyze maize canopy brightness temperature distribution. The measurement was carried out by using a TIR camera and a visible camera mounted on an industrial crane, the experiment lasted 3 months throughout maize growth cycle. In the analysis of component brightness temperature, Gaussian distirbution has been assumed. Results show the number of components and their brightness temperature values vary with time of day and biomass density. Three brightness temperature components of vegetation, sunlit and shaded soil could be identified at midday during the measurement period. In daytime, temperature variability of sunlit soil is much larger than the other two components when canopy's density is not high. When the canopy is full covered, vegetation brightness temperature has a wider range.
\end{abstract}

Keywords-component brightness temperatur;classification; maize canopy

\section{INTRODUCTION}

As one of physical parameters directly provided by remote observations, surface brightness temperature has been widely used to study energy budget of agricultural fields for determining canopy evapotranspiration, water stress, soil moisture, vegetation growing status. However, a major problem with this parameter in the applications is its spatial variability due to three dimensional structure of canopies and different thermal properties of canopy components (soil and vegetation) in an open canopy ecosystem. Being a solution in the modeling of energy budget and directional variations of emitted thermal radiation, surface brightness temperature is usually classified into several temperature components.

In order to describe the distribution of canopy surface brightness temperature, various methodologies have been utilised for brightness temperature component classification,

This study is supported by INRA France and China's Funds (Grant No. 2000077902, 2002AA130010-2, and CX020011) which were defined by temperature values, canopy components or combination of these two factors.

Many researchers revealed that brightness temperature components had temporal variations. In two experiments over cotton canopy, Kimes et al. and Kustas et al. [1, 2] showed sunlit soil temperature changed up to $30^{\circ} \mathrm{C}$ during the measuring day from the morning to the afternoon, shaded soil temperature generally follow the temporal trend of sunlit soil temperature with a $20^{\circ} \mathrm{C}$ amplitude, however, vegetation's brightness temperature varied within $10^{\circ} \mathrm{C}$.

Recently, an in situ experiment was conducted over a maize field in Avignon to investigate the variation of canopy brightness temperature distributions in order to interpret directional brightness temperature of a maize field. The objective of this paper is to identify the component number of brightness temperature of a maize canopy, then to investigate the relations among them and show their variability versus time of day as well as day of year during the growing period.

\section{MATERIALS AND METHODS}

\section{A. Definition of component brightness temperature}

For a natural canopy, the sensed radiance emitted by an elementary at position $(\mathrm{x}, \mathrm{y})$ within an infinitesimal range is [3]:

(1)

$$
R_{B, \lambda}(\theta, \varphi, x, y)=R\left(T_{B, \lambda}(\theta, \varphi, x, y)\right)=R\left(T_{b, \lambda}(\theta, \varphi, x, y)\right)+L_{\lambda}^{\prime}(\theta, \varphi, x, y)
$$

where $R_{B, \lambda}(\theta, \varphi, x, y)$ is directional spectral radiance emitted and reflected by an element at position (x, y); ${ }^{T_{B, \lambda}(\theta, \varphi, x, y)}$ is element directional brightness temperature derived from the radiance received by the detector; $T_{b, \lambda}(\theta, \varphi, x, y)$ is element directional brightness temperature derived from the radiance emitted by the element itself; $L_{\lambda}^{\prime}(\theta, \varphi, x, y)$ is the directional radiance due to the background contributors such as the incident radiance from sky and other part of the canopy.

In this research, the elements having similar brightness temperature value and belonging to the same canopy 
component (soil or vegetation) are collected as one brightness temperature component. Expanding the range of wavelength to the whole spectrum, equation (3) changes to be:

$a_{B} \sigma T_{B}^{4}(\theta, \varphi)=\sum_{k=1}^{N} f_{k}(\theta, \varphi) a_{k} \sigma T_{k}^{4}$

where $T_{B}(\theta, \varphi)$ is target's composite brightness temperature; $a_{B}$ is the ratio of thermal radiation in channel $i$ to that in whole wavelength range of the target; $a_{k}$ is the ratio of thermal radiation in channel $i$ to that in whole wavelength range for the component $\mathrm{k}, \sigma$ is the Stefan-Boltzmann constant.

\section{B. The studied maize canopy}

The experimental field locates at INRA-Avignon (43⒌' latitude and $4^{\circ} 5^{\prime}$ longitude) in France. It has a size of 150 meters long in North-South, 100meters width in West-Est direction. The maize was planted north-south oriented on May 10,1999 (Day of Year: DOY130) with a row distance of $0.8 \mathrm{~m}$ and the plant density is 9.32 plants per $\mathrm{m}^{2}$. The experiment lasted nearly three months from the end of May to the Beginning of August.

\section{The experimental setup}

The in situ experiment of component brightness temperature variations over a maize canopy was conducted by a camera-crane system. The system consists of one wide band TIR camera, a six-band visible-near infrared camera, an industrial crane and a multidirectional platform, which was mounted on the crane bar. The thermal camera and visible camera were set on the same platform with a distance of $0.4 \mathrm{~m}$. The TIR camera employed in the experiment was INFRAMETRICS Model 760. It equipped with a $80^{\circ}$ and a $7^{\circ}$ wide angle lens. The special window of the camera is $7.25 \mu \mathrm{m}$ to $13.25 \mu \mathrm{m}$.

In daytime measurement, wide lens was used for TIR camera, two cameras were set at 2 meter over the canopy to obtain maize field brightness temperature distribution. At the height, the pixel dimension of thermal images and visible images in footprint do not larger than $1 \mathrm{~cm}$ and $0.2 \mathrm{~cm}$. In night measurement, only TIR camera with $7^{\circ}$ lens was utilized, the altitude of the camera was changed to $20 \mathrm{~m}$, while the pixel's size is still less than $1 \mathrm{~cm}$. To acquire the data, the cameras firstly viewed their footprints, then inclined $45^{\circ}$ in the plane cross row direction to observe temperature profile of maize plant. In every direction, the imaging will last 20 seconds with a rate of one image per second. So there are about 20 images for one direction viewing, their average brightness temperature is used as true value to improve the measurement accuracy that the actual confidence interval $\left(\frac{2 \sigma}{\sqrt{n}}\right)$ changes to be $0.22^{\circ} \mathrm{C}$, where $\mathrm{n}$ is times of the measurement.

\section{Two approaches for the acquisition of brightness temperature components from thermal images}

The methodology utilised to analyse canopy brightness temperature components from the thermal images is histogramming and comparing the thermal images with the corresponding visible images. The process of histogramming for thermal images provides us histograms breaking up the horizontal axis of the brightness temperature into equal intervals, whereas the vertical axis represent the probability of temperature in each interval, the sum of the proportions for all interval is 1 . For canopy thermal images, several peaks appear in the histograms, according to the component definition, we suppose the number of these peaks is the number of canopy brightness temperature components, and the location of the peaks as the centers of brightness temperature components. It's norm rather than exception, different components might have the same temperature value, which lead two peaks in the histogram to overlap more or less. To extract the desired statistical parameters such as component's temperature range, least squares fitting of peak shapes was used to the composite. For example, if the peak shapes are supposed to be Gaussian and have known width, two fitted Gauss functions are iteratively adjusted until the difference between the actual and calculated data is minimised. Once the iterative minimum is researched, the area of each Gaussian function are the most probable estimates of component brightness temperature distribution.

The second method need imagery interpretation in the selection of component pixels. To locate the position and to directly acquire temperature range of each brightness temperature component, visible images were used as a conference. We distinguish sunlit and shaded soil and vegetation from visible images produced by combining three visible images of different bands (red, near infrared, and blue) to minimise the proportion of mixed pixels which are difficult to classify. The distribution of brightness temperature component is described by mean value $(\mu)$ and standard deviation $(\sigma)$ of each peak area, these two parameters are defined as $\mu=\frac{\sum_{i=1}^{n} T_{i}}{n}, \sigma=\sqrt{\frac{\sum_{i=1}^{n}\left(T_{i}-\mu\right)^{2}}{n}}$, where $n$ is the number of samples, $T_{i}$ is brightness temperature value of $i t h$ sample.

\section{RESULTS AND DISCUSSION}

Component brightness temperatures vary with the time of day. Figure 1 shows their temporal changes on Jun 24 when three measurements were conducted from morning to the afternoon. The measuring time are 9:19, 12:33 and 16:34 of local time respectively. During the measurement, there kept three components of vegetation, sunlit and shaded soil. Vegetation has the lowest brightness temperature, its brightness temperature increases steadily; sunlit soil has the highest brightness temperature. its temperature fluctuated quickly, the peak value appeared in the noon time; shaded soil's brightness temperature increase in the morning, while it keeps constant in the afternoon. Besides, its value is always near to that of vegetation component.
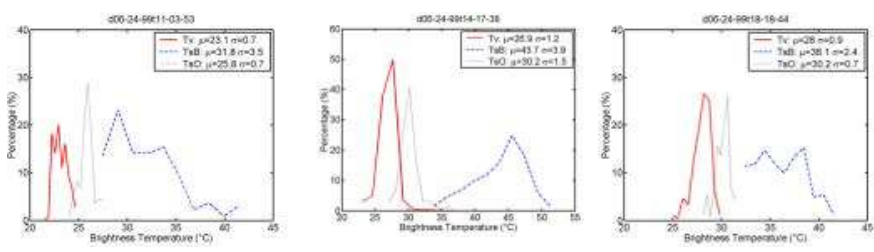

Figure 1. Three measurement of different time during the day of Jun 24, 1999: 9:18, 12:32 and 17: 03 of local time respectively. 
In the three measurements during the day, sunlit soil has the largest standard deviation $\left(3.5^{\circ} \mathrm{C}, 3.9^{\circ} \mathrm{C}, 2.4^{\circ} \mathrm{C}\right.$ at different time). This result has also been reported by Kustas et al. [3], he found the same results in his observations of a cotton field that brightness temperature of sunlit soil had the largest variability of brightness temperature. He attributed the reasons to the spatial difference of soil moisture and roughness of the soil surface.

To investigate the influence of geometrical structure on maize field component brightness temperature, more measurements were conducted around the midday from June to August. Table 1 lists statistical parameters of component brightness temperature such as component's mean temperature $(\mu)$, standard deviation $(\sigma)$.

Three components feature exists around midday during the whole measurement period. Before July 20 (DOY 201), standard deviations of sunlit and shaded soil are large, however, are still much less than the difference of their mean temperature, which lead the three components to be distinguished from each other. After July 20, although standard deviation decrease rapidly from $4^{\circ} \mathrm{C}$ to $0.5^{\circ} \mathrm{C}$, sunlit and shaded soil mean temperature differences decrease too, which lead the edge of the component turns blur.

Standard deviation of vegetation kept small which lead vegetation to have a rather stable temperature value. We link the reason to the thin feature of maize structure and evapotranspiration effect. With a thin geometrical structure, resistance of heat transfer is small, two sides of the plant that face to the incident solar radiation and back to the solar radiation may have a similar brightness temperature, evapotranspiration also reduce the temperature difference within the vegetation. This phenomena has also appeared in cotton observations [2]. As a comparison, dense canopy may have a wide brightness temperature range. Two sides of trees that face to and back to the sun radiation have a obvious brightness temperature difference [4]; upper part of sunflower has a large difference of brightness temperature with that of lower part [5].

The value order of three components brightness temperature changes with measuring date. Before July 20 (DOY 201), the order from high to low is sunlit soil, shaded soil and vegetation. After July 20 (DOY 201), the order changes to sunlit soil, vegetation and shaded soil or vegetation, sunlit soil and shaded soil. At least one of the main reason for this variability of value order is the changes of maize structure. High density canopy let less solar radiation penetrate and reach to soil surface and decrease time span that the soil is heated directly by sun radiation, in the mean time, the vegetation component is heated thoroughly. On contrary, sparse canopy let most the soil surface to be heated the sun, which lead to a higher value of sunlit soil brightness temperature.
TABLE I. TABLE OF FIELD TEMPERATURE PARAMETERS FOR DIFFERENT MEASURING DATE

\begin{tabular}{cccccccc}
\hline DATE & Jun. 16 & Jun. 24 & Jul. 2 & Jul. 9 & Jul. 20 & Jul. 30 & Aug. 6 \\
DOY & 155 & 175 & 183 & 190 & 201 & 211 & 218 \\
LOCAL & $13: 55$ & $12: 32$ & $10: 50$ & $13: 51$ & $13: 06$ & $14: 07$ & $10: 31$ \\
TIME & & & & & & & \\
$\mu$-Tv $\left({ }^{\circ} \mathrm{C}\right)$ & 31.1 & 26.9 & 28.8 & 30.5 & 30.6 & 28.2 & 31.5 \\
$\sigma$-Tv $\left({ }^{\circ} \mathrm{C}\right)$ & 1.5 & 1.2 & 1.3 & 1.0 & 0.8 & 0.5 & 0.8 \\
$\mu$-TsB $\left({ }^{\circ} \mathrm{C}\right)$ & 50.2 & 43.7 & 41.4 & 43.5 & 33.1 & 32.5 & 30.1 \\
$\sigma-\mathrm{TsB}\left({ }^{\circ} \mathrm{C}\right)$ & 2.2 & 3.9 & 3.3 & 4.1 & 1.7 & 0.9 & 0.5 \\
$\mu-\operatorname{TsO}\left({ }^{\circ} \mathrm{C}\right)$ & 37.2 & 30.2 & 31.2 & 35.8 & 30.0 & 29.9 & 28.7 \\
$\sigma-\mathrm{TsO}\left({ }^{\circ} \mathrm{C}\right)$ & 2.2 & 2.5 & 3.0 & 2.3 & 0.5 & 0.4 & 0.4 \\
\hline
\end{tabular}

The range of component temperature varies with date, it is affected by the geometrical structure of canopy. When maize density is low, temperature variability of soil components is very large. Besides the reason mentioned by Kustas et al. [2], the position and size of sunlit soil area are also very important. In the soil surface, parts of shaded and sunlit soil mixes together due to the complex 3D structure of the vegetation. Their temperatures difference in this kind of areas is smaller than that between large sunlit soil and large leaves, large size of sunlit soil usually has a higher temperature than that of a smaller sunlit surface. For a dense maize canopy, its capacity of temperature adjustment is improved, component thermal properties and canopy structure change to be constant and homogeneous, which lead the temperature variations within each component to decrease rapidly.

\section{CONCLUSION}

For the observations of maize brightness temperature distribution, we found number of components and component brightness temperature values vary with time of day and biomass density. Without sun shine, two brightness temperature components appeared; under direct solar irradiance, especially around the midday, three components could be identified through whole measurement period, which is different from the classification in visible band. During the whole measurement period, we haven't observed large fluctuation of vegetation brightness temperature, while soil brightness temperature changed quickly.

\section{REFERENCES}

[1] D.S. Kimes, J.A. Smith, and L.E. Link, "Thermal IR exitance of a plant canopy". Applied optics, 20(623-632). 1981.

[2] W. P. Kustas, "Ground and aircraft infrared observations over a partially-vegetated area". International journal of remote sensing, 11: 409-427, , 1990.

[3] L.P. Lagouarde, H. Ballans., P. Moreau, D. Guyon and D. Coraboeuf, "Experimental study of brightness surface temperature angular variations of maritime pine(pinus pinaster) stands". Remote sensing of environment, 72: 17-34, 2000

[4] P.M. Anthoni, E. L. Beverly, H. U. Michae and J. V. Richard, J.V., "Variation of net radiation over heterogeneous surface: measurements and simulation in a juniper-sagebrush ecosystem", Agricultural and Forest Meteorology, 102: 275-286, 2000.

[5] K. T. Paw U, S. L. Ustin and C. Zhang. "Anisotropy of thermal infrared exitance in sunflower canopies", Agricultural and forest meteorology, 47: 189-203. 1989 